\title{
Asian Science
}

A CASE STUDY

\section{An alternative of traditional learning : E-learning}

\author{
SUNIL NARBARIA*, V.K. PAINKRA, S. PRADHAN AND Y. DHRUV \\ Department of Agricultural Extension, Indira Gandhi Krishi Vishwavidyalaya, RAIPUR (C.G.) INDIA
}

\begin{abstract}
The present article is going to aware of people who stop their learning and don't want to continue their study due to some circumstances and for those who facilitated with modern technology like computer with faster internet connections. Elearning emerge as a strong alternative of traditional learning. Various public and private educational institutes offering various courses which are very effective to gain competitive skills for working in changing world. People can join these courses and full fill the requirement of professional skills.
\end{abstract}

Key Words : Learning, E-learning, Distance learning

View point paper : Narbaria, Sunil, Painkra, V.K., Pradhan, S. and Dhruv, Y. (2016). An alternative of traditional learning : E-learning. Asian Sci., 11 (2): 140-146, DOI : 10.15740/HAS/AS/11.2/140-146.

\footnotetext{
* Author for correspondence

Sunil Narbaria, Department of Agricultural Extension, Indira Gandhi Krishi Vishwavidyalaya, RAIPUR (C.G.) INDIA

(Email: sunilag22@gmail.com)
} 